\title{
OPTIMALISASI KETERAMPILAN BERBAHASA INGGRIS MELALUI PEMANFAATAN SOFTWARE PEMBELAJARAN BAHASA BAGI ANGGOTA KARANG TARUNA RT 01 RW 27 KADIPIRO SURAKARTA
}

\author{
Ulupi Sitoresmi dan Sumardiono \\ Pendidikan Bahasa Inggris, Fakultas Keguruan dan Ilmu Pendidikan, Universitas Slamet \\ Riyadi \\ Email: ulupisitoresmi27@gmail.com
}

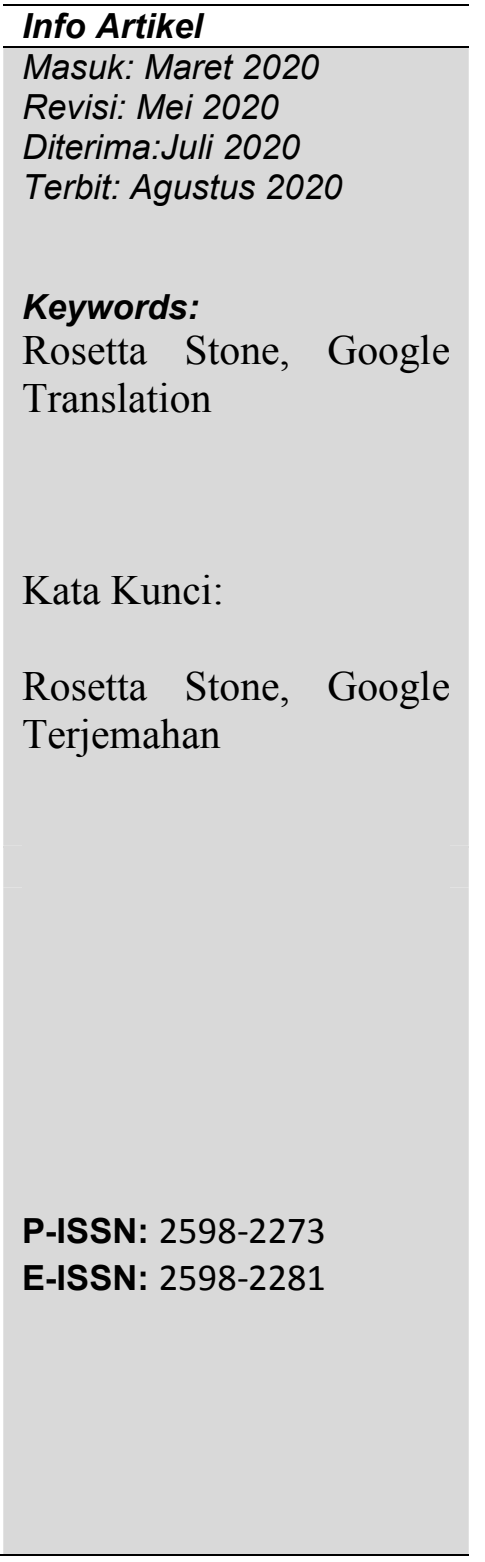

\begin{abstract}
This community service was conducted for Karang Taruna, a youth organnization, at Perum Graha Kencana $R T 01 R W$ 27 Kadipiro Surakarta. The focus was a training of using Rosetta Stone and Google Translation to improve English skills. The materials were delivered using three phases namely presentation, practise, and production. The training was beneficial for the participants specifically to improve their listening, speaking, reading, and writing skills as well as translation. Having adequate understanding of using Rosetta Stone and Google Translation, the participants were able to develop their English especially when completing school assignments.
\end{abstract}

Abstrak
Pengabdian masyarakat ini dilakukan untuk Karang Taruna,
sebuah organisasi pemuda, di Perum Graha Kencana RT 01
RW 27 Kadipiro Surakarta. Fokusnya adalah pelatihan
menggunakan Rosetta Stone dan Google Terjemahan untuk
meningkatkan keterampilan bahasa Inggris. Materi
disampaikan menggunakan tiga fase yaitu presentasi,
praktik, dan produksi. Pelatihan ini bermanfaat bagi peserta
secara khusus untuk meningkatkan keterampilan menyimak,
berbicara, membaca, dan menulis serta terjemahan. Memiliki
pemahaman yang memadai tentang penggunaan Rosetta
Stone dan Google Terjemahan, para peserta dapat
mengembangkan bahasa Inggris mereka terutama ketika
menyelesaikan tugas sekolah.

\section{PENDAHULUAN}

Kemajuan dan perkembangan teknologi menjadi fenomena yang sangat dekat dengan masyarakat dunia saat ini. Tidak terhitung dalam jam bahkan detik berbagai 
produk teknologi baik perangkat keras (hardware) maupun perangkat lunak (software) dapat diakses dengan mudah melalui internet dan telepon pintar (smartphones). Hadirnya produk-produk teknologi ini tentu saja membawa dampak baik positif maupun negatif bagi penggunanya (Trisiana, A.dkk. 2019). Untuk itulah pemahaman yang memadai dan menyeluruh baik dari sisi pengetahuan maupun ketrampilan perlu dimiliki oleh setiap pengguna agar dapat memanfaatkan hasil teknologi secara efektif, efisien, dan bijaksana. Menyiapkan generasi penerus bangsa Indonesia yang mampu bersanding dan bersaing dalam interaksi global menjadi hal yang harus dilakukan dan didukung oleh berbagai elemen dalam masyarakat (keluarga, masyarakat, sekolah, dan negara). Hal ini sejalan dengan sambutan Menteri Pendidikan dan Kebudayaan di dalam buku " Materi Pendukung Literasi Digital" (2017) tertulis bahwa syarat kecakapan hidup abad-21 adalah budaya literasi dan dalam World Economic Forum tahun 2015 disepakati bahwa penguasaan enam literasi dasar (literasi baca tulis, literasi numerasi, literasi sains, literasi digital, literasi finansial, dan literasi budaya dan kewargaan harus dimiliki. (Trisiana, A. 2020); Wartoyo, Anita Trisiana. 2020).

Salah satu bidang yang turut terimbas kemajuan teknologi ini adalah bidang pendidikan termasuk di dalamnya pembelajaran bahasa. Berbagai aplikasi dan perangkat digital dikembangkan secara khusus untuk mendukung keberhasilan proses belajar mengajar dan pengembangan ketrampilan berbahasa. Teknologi mampu menciptakan kesempatan besar baik bagi pebelajar bahasa dan pengajar yaitu penggunaan bahasa secara riil di kelas dan lingkungan kelas yang lebih interaktif.(Carrier, 2017). Beberapa software pembelajaran bahasa yang telah banyak digunakan dan menjadi obyek penelitian antara lain Microsoft Encarta, Duolingo,Rosetta Stone, dan Google Translate. Terlepas dari kecanggihan piranti ini masing-masing memiliki sisi kelemahan yang memungkinkan tidak optimalnya hasil belajar. Oleh karena itu para pengguna perlu dibekali dengan pengetahuan dan teknik menggunakan piranti ini agar mencapai hasil yang maksimal. Terutama bagi para pelajar piranti tersebut sangat bermanfaat untuk menyelesaikan tugas sekolah. Sebagai contoh siswa acapkali diberikan tugas menerjemahkan sebuah teks berbahasa Inggris kedalam Bahasa Indonesia. Google Translate merupakan salah satu aplikasi yang dapat membantu siswa menyelesaikan tugas tersebut. 
Di masyarakat keberadaan Karang Taruna tidak asing lagi karena merupakan wadah bagi generasi muda (sebuah organisasi kepemudaan). Didalam kehidupan bermasyarakat keberadaan Karang Taruna sudah tidak asing lagi dari jaman dahulu hingga era milenial ini. Karang Taruna sebagai sebuah organisasi kepemudaan mewadahi seluruh pemuda yang pada umumnya berusia antara 13-19 tahun. Demikian pula dilingkungan RT 01 RW 27 kadipiro memiliki karang taruna yang masih aktif. Mayoritas para anggotanya duduk dibangku SMP dan SMA.

Berdasarkan observasi para anggota karang taruna tersebut sangat aktif dan intens dalam menggunakan gadget/ gawai setiap hari. Pada saata mereka bertemu mayoritas menggunakan gawai untuk 'game' (PUBG, Mobile Legend, Free Fire ) yang memang sangat populer dikalangan anak muda saat ini. Dari hasil wawancarapun diketahui mereka memanfaatkan gawai untuk sosial media. Hanya sesekali saja mereka menggunakan untuk belajar khususnya ketika ada tugas dari guru di sekolah. Mereka juga tidak mengetahui terdapat banyak aplikasi baru seperti Duolingo, Grammarly, Speakonia, atau Rosetta Stone yang dapat dimanfaatkan khususnya untuk meningkatkan kemampuan berbahasa, hanya sesekali saja mereka menggunakan 'google terjemahan' untuk mengerjakan tugas menerjemahkan yang acapkali di berikan di pelajaran Bahasa Inggris. Meskipun mereka sudah menggunakan aplikasi 'google terjemahan' nampaknya hasil terjemahannya belum maksimal karena mereka juga tidak dibekali pengetahuan yang memadai tentang bagaimana menggunakan aplikasi tersebut agar menghasilkan terjemahan yang berkualitas (akurat, berterima, dan terbaca).

Berangkat dari permasalahan yang terjadi di Karang Taruna RT 01 RW 27 kadipiro tersebut khususnya dalam hal pemanfaatan software pembelajaran bahasa, maka Tim pengabdian pada masyarakat melaksanakan kegiatan berupa Pemanfaatan Software Pembelajaran Bahasa Untuk Meningkatkan Keterampilan Berbahasa Inggris Bagi Anggota Karang Taruna RT 01 RW 27 Kadipiro. 


\section{METODE PELAKSANAAN}

Mengacu pada permasalahan dan kondisi riil dilapangan metode pelaksanaan yg digunakan berupa pelatihan pemanfaatan software pembelajaran bahasa. Fokus pelatihan dibagi dalam dua tahap sebagai berikut :

Tahap I Pelatihan Rosetta Stone

a. Peserta mengunduh aplikasi Rosetta Stone

Pada tahap ini seluruh peserta mengunduh Rosetta Stone di App store atau Google Play menggunakan handphone masing - masing.

b. Peserta mendengarkan pemaparan tim.

Tim memaparkan berbagaii fitur yang tersedia di Rosetta, manfaatnya untuk meningkatkan ketrampilan berbahasa, dan cara menggunakannya.

c. Peserta berlatih mempraktikkan belajar bahasa dengan aplikasi Rosetta Stone Tahap II Pelatihan 'Google Terjemahan'

a. Peserta mengunduh aplikasi 'Google Terjemahan'

Aplikasi ini dapat diunduh oleh masing-masing peserta di App Store atau Google Play.

b. Peserta mendengarkan pemaparan tim.

Pemaparan yang disampaikan Tim mencakup penerjemahan secara umum, penjelasan berbagai fitur di aplikasi ini (4 fitur), serta teknik untuk menghasilkan terjemahan yang baik dengan bantuan Google terjemahan.

c. Peserta berlatih mempraktikkan menerjemahkan dengan aplikasi 'Google Terjemahan' yang terdiri dari 4 fitur.

Masing-masing tahapan dilaksanakan dengan metode 3P yaitu presentation, practise, dan production.

\section{PEMBAHASAN}

Kegiatan pelatihan pemanfaatan software pembelajaran bahasa ini diikuti oleh 12 orang anggota Karang Taruna RT 01 RW 27 Kadipiro. Pelatihan dilaksanakan pada tanggal 27 September 2019 dan 4 Oktober 2019.

Pelatihan Rosetta Stone disampaikan kepada peserta untuk meningkatkan empat keterampilan berbahasa (Inggris). Minimal peserta di perkenalkan fitur-fitur yang ada di Rosetta Stone dan cara menggunakannya. 
Rosetta Stone sendiri menarik untuk digunakan karena didalamnya \& lengkapi materi untuk belajar empat keterampilan berbahasa yaitu Listening (menyimak), Speaking (berbicara), Reading (membaca), dan Writing (menulis). Selain itu peserta juga dapat berlatih berbagai elemen bahasa yaitu pronunciation (pengucapan), grammar (tata bahasa), dan vocabulary ( kosa kata ). Pelatihan tahap I dilaksanakan pada 27 September 2019 dan diikuti 12 peserta.

Setelah mengunduh aplikasi Rosetta Stone, peserta diberi kesempatan ( tiga orang perwakilan ) untuk mempraktikkan dengan menggunakan laptop tim pengabdian sementara peserta lainnya praktik menggunakan smartphone masingmasing. Peserta pertama mempraktikkan latihan kosa kata pada level dasar. Peserta kedua dan ketiga mempraktikkan latihan structure (tata bahasa). Diakhir pelatihan ini para peserta mengetahui dan dapat menggunkan Rosetta Stone untuk belajar bahasa Inggris secara mandiri.

Pelatihan Tahap II yang dilaksanakan pada 4 Oktober 2019 dan diikuti 12 orang peserta ini terfokus pada pemanfaatan 'google terjemahan' khususnya untuk menerjemahkan teks berbahasa Inggris ke dalam bahasa Indonesia dan sebaliknya.

Berdasarkan observasi tim sebelum pemaparan materi peserta belum mampu menggunkana 'google terjemahan' secara optimum. Sebagai contoh pada saat peserta diminta menerjemahkan sebuah teks berbahasa Inggris dengan fitur 'scan camera' di aplikasi tersebut mayoritas peserta langsung scan keseluruhan teks. Tim selanjutnya meminta peserta mengulang dengan scan teks per paragraf. Peserta diminta untuk membandingkan hasilnya dimana dengan teknik yang kedua hasil terjemahan lebih akurat dan berterima. Latihan berikutnya yaitu penggunaan fitur Voice (suara). Di sini peserta dibekali tips agar terjemahannya akurat. Pada dasarnya fitur ini sudah mampu mengenali berbagai macam kata kerja dalam Bahasa Inggris sesuai waktunya. Sebagai contoh pada saat salah satu peserta mengucapkan "Kemarin saya makan nasi" hasil terjemahan dari aplikasi ini "Yesterday I ate rice". 


\section{PENUTUP}

Agar terjemahan terutama pada bagian kata kerja bentuknya tepat maka peserta disarankan mengucapkan kalimatnya lengkap dengan keterangan waktunya. Langkah-langkah tersebut diatas dilakukan tim pada saat mendampingi peserta praktik menggunkan 4 fitur dalam google terjemahan. Hasil dari kegiatan ini peserta mengetahui sekilas tentang penerjemahan, cara menggunakan 4 fitur dalam google terjemahan, kelemahan dan kelebihan masing-masing fitur, dan mampu menghasilkan terjemahan yang lebih akurat dan berterima.

\section{DAFTAR PUSTAKA}

Bates. 2016. Teaching in Digital Age. Cambridge. Cambridge University Press.

Carrier,M.,Damerow,R.M.,\&Bailey,K.M. 2017. "Digital Language Learning and Teaching: Research,Theory, and Practice" . New York: Routledge.

Collins,A.,\& Halverson, R. 2009. Rethinking Education in The Age Technology. The Digital Revolution and Schooling in America. New York, NY: Teachers College Press.

Puspitasari,D.N.,2018. Improving Students' Listening Skill Using Rosetta Stone Software. A Thesis. Universitas Slamaet Riyadi.

Tim GLN.2017. "Materi Pendukung Literasi Digital" . Jakarta Kementrian Pendidikan dan Kebudayaan

Trisiana, A. 2020. Digital Literation Models For Character Education In Globalization Era : Digital Literation Models. Humanities \& Social Sciences Reviews, 8(1), 522-531. Https://Doi.Org/10.18510/Hssr.2020.8164

Trisiana, A. Sugiaryo, Rispantyo. 2019. Model Desain Pendidikan Kewarganegaraan di Era Digital sebagai Pendukung Sebagai Implementasi Pendidikan Karakter. Jurnal Civic Media Kajian Kewarganegaraan. Vol 16 (2). Pp 154-164

Wartoyo, Anita Trisiana. 2020. Project Citizen: Innovation And Challenges Of Education Learning Models To Improve Millenial Generation Characters. Journal of critical reviews (JCR) Volume: 7, Issue: 11: 750-754. DOI: $10.31838 /$ jcr.07.11.134 